\title{
Comparison of eight degree-days estimation methods in four agroecological regions in Colombia
}

\author{
Daniel Rodríguez Caicedo( $\left.{ }^{1 *}\right)$; Jose Miguel Cotes Torres $\left({ }^{2}\right)$; José Ricardo Cure( $\left.{ }^{1}\right)$ \\ (') Universidad Militar Nueva Granada, Facultad de Ciencias Básicas, Cra. 11\#101-80 Bogotá, Colombia. \\ (2) Universidad Nacional de Colombia, Departamento de Ciencias Agropecuarias, Calle 59a\#63-20, Medellín, Colombia. \\ (*) Corresponding author: daniel.rodriguez@unimilitar.edu.co
}

Received: Sept. 20, 2011; Accepted: Mar. 8, 2012

\begin{abstract}
Eight methods were used to estimate degree-days in four Colombian localities. Four methods have been previously proposed in literature: Simple Sine, Double Sine, Simple Triangle, and Double Triangle methods. The other four methods are proposed in this research: Simple Logistic, Double Logistic, Simple Normal, and Double Normal. The estimation of the degree-days through hourly temperature values was used as the reference standard method, and the four localities from where the temperature values were taken were the municipalities of Cajicá (Cundinamarca), Santa Elena (Antioquia), Carepa (Urabá Antioqueño), and Ciudad Bolivar (Zona cafetera Antioqueña). Degree-days obtained by all methods under study were compared through linear regression to those obtained by the reference standard method. There were differences in the correlation of each method to the reference when compared within each region and among regions. The Simple Logistic and Double Logistic methods showed the best performance with acceptable $\mathrm{R}^{2}$ values and considerably lower bias than the other methods. The poorest fit was found in Cajicá, where the average $\mathrm{R}^{2}$ was 0.571. For the regions of Santa Elena and Carepa, the average $\mathrm{R}^{2}$ was 0.756 and 0.733 . The best fit was found in Ciudad Bolivar, with an average $\mathrm{R}^{2}$ of 0.826 .
\end{abstract}

Key words: degree-days, thermal time, temperature threshold, statistical modeling.

\section{Comparação de oito métodos para calcular graus-dia em quatro regiões agroecológicas}

\section{Resumo}

Estimativas de graus-dia foram obtidas pelos métodos de seno simples e duplo, triangulo simples e duplo, as quais são amplamente utilizadas. Quatro novos métodos foram propostos e avaliados nesta pesquisa: logística simples e dupla, normal simples e dupla, baseadas em regressão logística e distribuição normal. Registros horários de temperatura obtidos em Cajicá (Cundinamarca), Santa Elena (Antioquia), Carepa (Urabá Anţioqueño) e Ciudad Bolivar (Região tradicional da cultura do café) foram utilizados para obter estimativas da soma térmica com maior precisão sendo, portanto, considerada como a referência para comparação utilizando regressão linear. Foram constatadas diferenças entre o ajuste dos métodos dentro de cada região e entre regiões. Foram observados os maiores coeficientes de determinação $\left(R^{2}\right)$, nos métodos de logística simples e logística dupla. O menor coeficiente de determinação, de 0,571, foi obtido em Cajicá enquanto nas regiões de Medellín e Carepa, o $\mathrm{R}^{2}$ foi de 0,756 e 0,733 respectivamente. O melhor ajuste foi obtido em Ciudad Bolivar, com um $\mathrm{R}^{2}$ igual a 0,826.

Palavras-chave: graus-dia, tempo térmico, temperatura basal, modelagem estatística.

\section{INTRODUCTION}

The concept of degree-days has been widely used in agriculture, especially to quantify and predict phenological events, because it is more accurate than using chronological time or the predictions of events according to the season of the year (MCMASTER and Wilhelm, 1997). Degree-days have been used in phenological analysis applied to different kind of crops, both in temperate zones (NARWAL et al., 1986; Allen and O'brien, 1986; Undersander and Christiansen, 1986; Jones et al., 1991; Sharratt et al., 1989; Spencer et al., 2000; Spencer and Ksander, 2006) and in tropical zones as well (Lemos et al., 1997; McBeth et al., 2001; Bell and Wright, 1998; Jullien et al., 2008; Guan et al., 2009). Degree-days also have been used in insect phenology studies (ToKeshi, 1985; Lindblad and Sigvald, 1996; Hart et al., 1997; Broufas and Koveos, 2000; Milonas et al., 2001; Olsen, 2003; Hirata and Higashi, 2008; Kumral et al., 2008; Naves and Sousa, 2009; Nietschke et al., 2007; ELLiot et al., 2009).

The basic equation for the calculation of degreedays is (MCMAster and WilHeLm, 1997):

$D D=\frac{T_{\max }+T_{\min }}{2}-M T T$ 
Where $D D$ are the degree-days, $T_{\max }$ and $T_{\min }$ are the daily maximum and minimum temperatures, respectively, and $M T T$ is the minimum temperature threshold. In [1] it is assumed that if $\left[\left(T_{\max }+T_{\text {min }}\right) / 2\right]>M T T$, then $\mathrm{DD}>0$, but if $\left[\left(T_{\max }+T_{\min }\right) / 2\right]<M T T$, there is no accumulation of thermal time and $\mathrm{DD}=0$. Equation [1], however, can underestimate degree-days when temperatures fluctuate above and below the minimum threshold. The reason for this underestimation is that organisms grow and develop during the periods of the day when the temperature is above the minimum temperature threshold, even if at the end of the day the daily average temperature is lower than that minimum threshold. Some methods based on the daily temperature fluctuation pattern have been proposed in order to correct this problem. The most widely used of these methods, from the simplest to the more complex, are: Simple Triangle, Double Triangle, Simple Sine and Double Sine. These methods assume that the minimum daily temperature is reached at midnight, while the maximum daily temperature is reached at noon; these methods also allow consideration of a maximum temperature threshold above which the organism of interest doesn't progress. There is scant information about comparisons among the different methods. RolTsCH et al. (1999) evaluated the above-mentioned four methods in California climates. They found that compared to the Simple Sine and Simple Triangle methods, the Double Sine and Double Triangle methods did not offer a significant improvement in the estimation of degree-days. The same authors found differences in the performances of the methods when used in different regions; these results indicate that a method considered functional in a region might not be the best one for other regions, and therefore it is recommended to evaluate different methods and determine which one is superior for a specific region. To date, this research is the first in Colombia addressing that goal. The purpose of this research was to evaluate four previously published methods to estimate degree-days in four Colombian regions, and compare them to four new methods proposed in this study.

\section{MATERIAL AND METHODS}

All the estimations in this research were done using hourly temperature data from four weather stations: (1) the weather station at Rio Grande experimental farm in Cajicá, Cundinamarca, located at an altitude of 2558 $\mathrm{m}$. with an annual average temperature of $14{ }^{\circ} \mathrm{C}(57.2$ ${ }^{\circ} \mathrm{F}$ ), classified as a Lower Montane dry forest life zone according to the Holdridge life zone system, and from where 364 days of data were used; (2) the weather station at Paisandú experimental farm in Santa Elena, Antioquia, located at $2500 \mathrm{~m}$., with an annual average temperature of $14{ }^{\circ} \mathrm{C}\left(57.2^{\circ} \mathrm{F}\right)$ and classified as a Lower Montane humid forest life zone; the data analyzed from this station included 304 days of hourly temperatures; (3) the Augura weather station in Carepa, Antioquia, located at an altitude of $40 \mathrm{~m}$., with an annual average temperature of $25^{\circ} \mathrm{C}\left(77^{\circ} \mathrm{F}\right)$, classified as a Tropical humid forest life zone, and from where 181 days of data were analyzed; (4) the weather station in Ciudad Bolivar, Antioquia, located at $1429 \mathrm{~m}$., with an average annual temperature of $22^{\circ} \mathrm{C}$ $\left(71.6^{\circ} \mathrm{F}\right)$, and classified as a Premontane humid forest life zone; the data used from this station included 128 days of hourly temperatures.

The data were classified according to the six possible situations that can occur when comparing daily temperature curves with the temperature thresholds: (1) the minimum temperature is higher than the minimum threshold and the maximum temperature is higher than the maximum threshold; (2) the minimum temperature is lower than the minimum threshold and the maximum temperature is higher than the maximum threshold; (3) both maximum and minimum temperatures are within thresholds; (4) the minimum temperature is lower than the minimum threshold and the maximum temperature is lower than the maximum threshold; (5) both minimum and maximum temperatures are higher than the maximum temperature threshold, and (6) both maximum and minimum temperatures are lower than the minimum threshold. The methods previously published, and the new methods proposed here allow making adjustments to include the effect of each of the six described situations. In order to evaluate the six methods within each location, both the minimum and maximum temperature thresholds were estimated as the average of the minimum and maximum daily temperatures for the evaluation period, respectively. In this way, an approximately equal number of data was assigned to each method.

Two approaches have been proposed for the cases when the maximum daily temperature is higher than the maximum temperature threshold (RoLTsch, 1999): (1) the Vertical Cutoff method considers that there is no accumulation of thermal time when the maximum temperature rises above the maximum temperature threshold; (2) the Horizontal Cutoff method assumes that thermal time keeps accumulating when temperature is above the maximum temperature threshold, but the difference between the maximum temperature and the maximum threshold doesn't contribute to the accumulated thermal time. The latest approach was used in this research.

Four methods previously discussed in literature were evaluated in this study: Simple Triangle (Lindsey and Neuman, 1956), Double Triangle (Sevacherian et al., 1977), Simple Sine (Baskerville and Emin, 1969), and Double Sine (Allen, 1976). Equations and mathematical issues about each one of the four methods can be found in the original papers and are not shown here. Additionally, four new methods were proposed and evaluated: Simple 
Logistic, Double Logistic, Simple Normal, and Double Normal. The first two methods assume that temperatures fluctuate during the day according to a logistic model and the last two methods assume that temperatures fluctuate during the day according to a normal distribution. All the new methods also allow for appropriate adjustments according to the six different situations that can occur when comparing the daily temperature curve with the minimum and maximum thresholds.

\section{Symmetric Methods}

One of the approaches to degree-day modeling is to assume that the temperature curve is symmetric around the maximum temperature. The following methods use this approach.

Simple Triangle (Lindsey and Neuman, 1956): In this method, a straight line is drawn from the minimum temperature, assumed at 00:00 hours, to the maximum temperature, assumed at 12:00 hours, and from there, to complete the two sides of a triangle, another straight line is drawn to the next day's minimum temperature, which is assumed to be the same minimum temperature used for the first half of the day (Figure 1a). The accumulated degree-days are estimated as the area under the triangle and between the thresholds. As can be seen from the figure, temperature fluctuations do not necessarily behave according to the assumptions of the method and for the first two days the method overestimates the degree-days during the morning and underestimates them in the afternoon. The third day, the method overestimates the degree-days both in the morning and in the afternoon.

Simple Sine (Baskerville and Emin, 1969): As can be seen from figure $1 \mathrm{c}$, the changes in temperature are closer to a soft curve than to a straight line as assumed in the Simple Triangle method. By assuming that the variation of daily temperatures follows a sine function closely, the Simple Sine method offers a better approximation of the curvilinear behavior of the temperature. As in the previous method, the minimum daily temperature is the same for both halves of the day and degree-days are estimated as the area under the sine curve and between the thresholds.

Simple Logistic (proposed): This method is based on the logistic model and assumes that in each half of the day the temperature fluctuates according to the logistic equation (Fox, 2002). As in the Simple Sine and Simple Triangle methods, it is assumed that temperatures are symmetric around the maximum temperature (Figure 1e). In [2] $T$ is the temperature expressed as a function of the hour of the day, $t$. The parameter $\beta_{1}$ is the day's maximum temperature, $\beta_{2}$ indicates the temperature at 00:00, and $\beta_{3}$ controls the rate of temperature change.

$$
T=\frac{\beta_{1}}{1+e^{\beta_{2}+\beta_{3} t}}
$$

Assuming as in the previous models that the minimum temperature, $T_{\text {min }}$, is reached at 00:00 hours, the parameter $\beta_{2}$ can be obtained as follows:

$\beta_{2}=\log _{e}\left(\frac{\beta_{1}}{T_{\text {min }}}-1\right)$

Since different models assume that the minimum temperature occurs at 00:00 hours and the maximum at 12:00 hours, it was considered reasonable to assume that $\left(T_{\max }+T_{\min }\right) / 2$ occurs at 6:00 hours; this allows a third temperature value that can be used to estimate $\beta_{3}$ and complete the parameters of the model.

$\beta_{3}=\frac{\left[\log _{e}\left(\frac{T_{\text {max }}}{T_{\text {max }}+T_{\text {min }}}-1\right)-\beta_{2}\right]}{6}$

Degree-days are estimated by solving the integral of model [2] between 0 and 12. Since the integration is solved considering time as an independent variable expressed in hours, the result of the integration is an estimation of degree-hours, therefore this value has to be divided by 24 to become degree-days, and then multiplied by 2 because it is assumed that the thermal accumulation is the same for the two halves of the day.

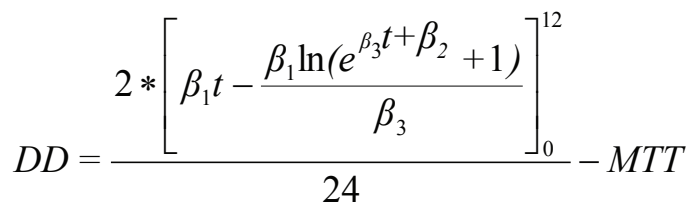

The necessary adjustments to the six situations previously described in the introduction can be implemented by using the inverse function of [2] to find the hour of the day in which a specific threshold is reached, and limiting the integral to the appropriate range of hours.

Simple Normal (proposed): In this proposal it is assumed that in each half of a day temperature fluctuates according to the density function of a normal distribution with $\mu=12$ and $\sigma=4.5$ and, multiplied by an appropriate value $(K)$ [4]. The value of the parameter $\sigma$ was chosen to allow for a better adjustment of the curve to temperature fluctuations along the day under tropical conditions. This function tends to zero at 00:00, the 


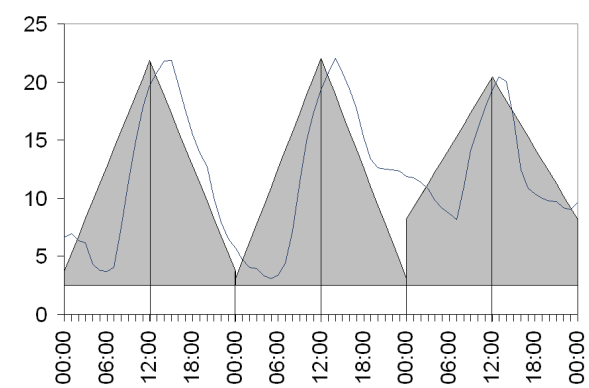

(a)

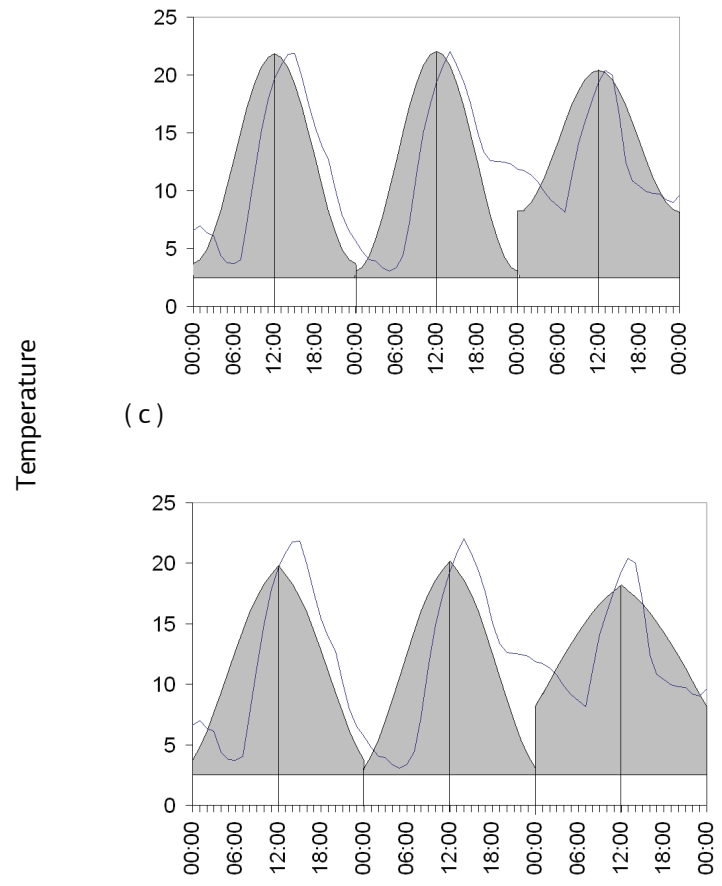

(e)

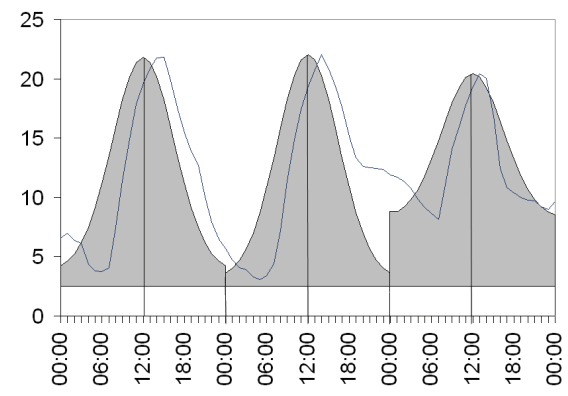

(g)

Hour of day

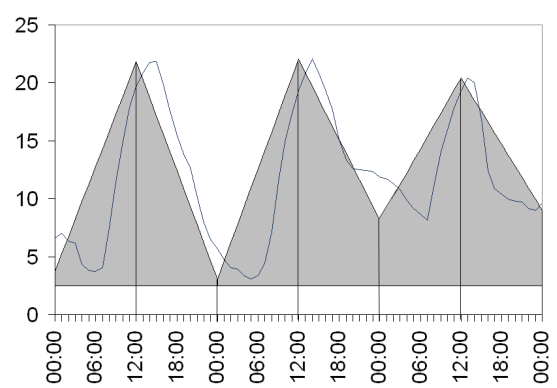

(b)
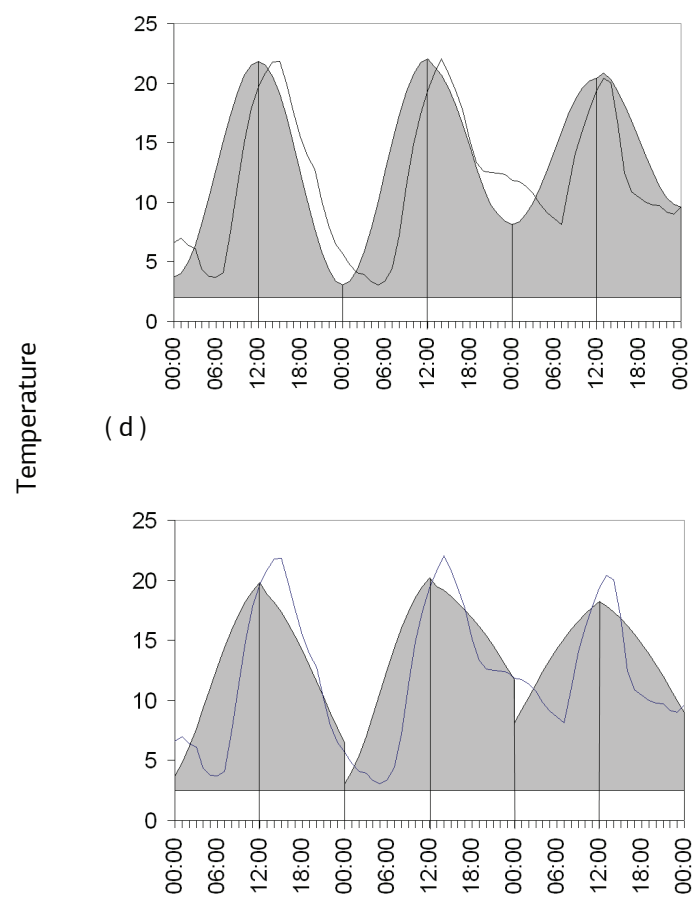

(f)

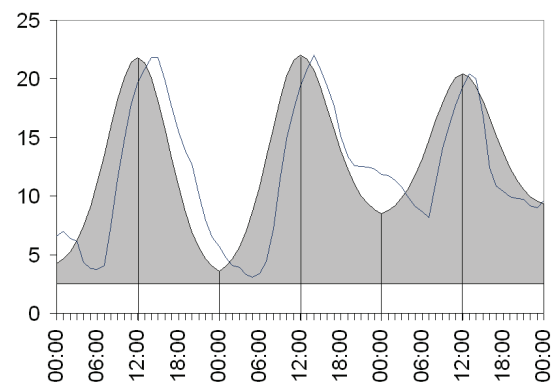

(h)

Hour of day

Figure 1. Graphic comparison of the evaluated degree-day estimation methods. The X-axis represents the hours of the day during a period of three days. The Y-axis represents the temperatures during the day. The blue line shows the observed temperatures during three days in Cajicá, Cundinamarca. The gray area represents the degree-days accumulated by each of the following methods: (a) Simple Triangle, (b) Double Triangle, (c) Simple Sine, (d) Double Sine, (e) Simple Logistic, (f) Double Logistic, (g) Simple Normal, and (h) Double Normal. 
time when the minimum temperature is reached, and is equal to $T_{\max }-T_{\min }$ at 12:00, the time when the maximum temperature is reached (Figure $1 \mathrm{~g}$ ).

$T(t)-T_{\min }=\frac{1}{\sqrt{2 \cdot 4.5 \cdot \pi}} e^{-0.5 \cdot[(t-12) / 4.5]^{2}} \times K$

where

$K=\left[\frac{\left(T_{\max }-T_{\min }\right) \sqrt{2 \cdot 4.5 \cdot \pi}}{e^{-0.5 \cdot[(12-12) / 4.5]^{2}}}\right]$

simplifying [3] and [4] :

$$
T(t)-T_{\min }=e^{-0.5 \cdot[(t-12) / 4.5]^{2}}\left(T_{\max }-T_{\min }\right)
$$

Since the integral of a normal density function is equal to 1 , the integral of [5] is equal to $K$. Therefore, to obtain the area under the curve of the expression [5], the probabilities of a standard normal distribution can be used and multiplied by the mentioned value $K$. To calculate the probabilities, 00:00 and 12:00 are transformed into values of a standard normal distribution $(\mathrm{z}=-2.67$ and $\mathrm{z}=0.00$, respectively), and the degree-days can be obtained as indicated in (6):

$$
\begin{aligned}
D D= & T_{\min }+2 *[p(z<0.0)-p(z<-2.67)] * \\
& {\left[\frac{\left(T_{\max }-T_{\min }\right) \sqrt{2 \cdot 4.5 \cdot \pi}}{24 * e^{-0.5 \cdot[(12-12) / 4.5]^{2}}}\right]-M T T }
\end{aligned}
$$

It is divided by 24 and multiplied by 2 for the same reasons already explained in the discussion of the Simple Logistic method. The necessary adjustments to the six situations previously described in this section can be implemented by using the inverse function of the normal density function to determine the hour in which a specific threshold is reached, which allows limiting the calculation of probabilities to the appropriate range of hours.

\section{Asymmetric Methods}

Daily temperatures do not necessarily fluctuate symmetrically around the maximum temperature, which could lead the previous methods to inaccurate degree-day estimations. The following so-called "double" methods attempt to correct this situation by considering different minimum temperatures for each half of the day. In these methods, the minimum temperature for the first half of the day is the actual minimum temperature of the day while the minimum temperature for the second half of the day is the minimum temperature of the following day. For these methods, the necessary adjustments to the six situations mentioned above are done for each half of the day.

Double Triangle (Sevacherian et al., 1977): The degree-days for the day are calculated as the sum of the degree-days for the two half-days, which are estimated as the area within the triangle and between the thresholds (Figure 1b).

Double Sine (Allen, 1976): This method fits a different sine curve for each half of the day using the appropriate minimum and maximum temperatures (Figure 1d). The degree-days are calculated as the sum of the areas under the curves and between the thresholds (MCMAsTER and Wilhelm, 1997).

Double Logistic (proposed): The procedure is similar to that described for the Simple Logistic method, but in this case it is necessary to estimate the parameters and to integrate separately for each half of the day. The parameter $\beta_{1}$ is the same for both halves of the day, but for each half of the day, $\beta_{2}$ and $\beta_{3}$ must be estimated using the appropriate $T_{\min }$ value (Figure 1f).

Double Normal (proposed): The procedure is also similar to that described for the Simple Normal method, but the value of $K$ has to be estimated for each half of the day based on the appropriate minimum temperature. (Figure 1h).

\section{Comparison of Methods}

The estimation of degree-days through the area under the curve of hourly temperatures was considered the reference standard method because this procedure is more accurate than the methods that use minimum and maximum temperatures. The integration was solved using the midpoint rule.

In order to evaluate the eight methods under study, linear regression models were estimated for each combination of method and locality. The dependent variable was the degree-days estimated by each of the methods and the independent variable was the degree-days calculated with the reference standard method. Fitting performance of the models was evaluated through the coefficient of determination $\left(\mathrm{R}^{2}\right)$, and the bias of the model. The bias was defined as the percentage difference between the accumulated degree-days or thermal time (Total GD) obtained with each method for the evaluated period and the accumulated degree-days estimated with the reference standard method. 


\section{RESULTS AND DISCUSSION}

\section{Cajicá, Cundinamarca}

The intercepts for the Simple Triangle, Double Sine, and Simple Normal methods were statistically significant according to Student's t-test. From the new methods, only the Double Normal had a statistically significant intercept. The four methods previously proposed in literature showed values of bias around $18 \%$, a value close to that of the Double Normal method which had the highest bias (18.43\%). The Simple Logistic and Double Logistic methods presented significantly lower bias, indicating a better estimation of the accumulated degree-days. Considering the $\mathrm{R}^{2}$ alone, the best fit was shown by the Simple Triangle and Simple Sine methods, followed by the Simple Logistic method. The two first methods, however, had high bias and therefore the Simple Logistic method is a better option for the estimation of accumulated degree-days in this region. The Double Normal method had the highest bias and the lowest $\mathrm{R}^{2}$, therefore its use is not recommended for this locality.

Table 1. Results for the eight evaluated methods in four localities.

\begin{tabular}{|c|c|c|c|c|c|}
\hline Method & $\hat{\boldsymbol{\beta}}_{0}$ & $\hat{\boldsymbol{\beta}}_{1}$ & $\mathbf{R}^{2}$ & Total GD ${ }^{*}$ & Bias \\
\hline \multicolumn{6}{|c|}{ Cajicá } \\
\hline Simple Triangle & $0.05615^{* *}$ & $1.1662^{* *}$ & 0.6245 & 1767.630 & 17.98 \\
\hline Simple Sine & 0.4442 & $1.0701^{* *}$ & 0.6351 & 1764.990 & 17.81 \\
\hline Double Triangle & 0.3812 & $1.0876^{* *}$ & 0.5588 & 1768.300 & 18.03 \\
\hline Double Sine & $0.7426^{* *}$ & $0.9979 * *$ & 0.5688 & 1765.470 & 17.84 \\
\hline Simple Logistic & -0.3015 & $1.1875^{* *}$ & 0.6129 & 1669.384 & 11.43 \\
\hline Simple Normal & $-1.4140^{* *}$ & $1.4735^{* *}$ & 0.5291 & 1692.939 & 13.00 \\
\hline Double Logistic & 0.03695 & $1.10578^{* *}$ & 0.5446 & 1670.084 & 11.47 \\
\hline Double Normal & 0.5365 & $1.3146^{* *}$ & 0.4954 & 1774.264 & 18.43 \\
\hline Ref. Standard & & & & 1498.161 & \\
\hline \multicolumn{6}{|c|}{ Santa Elena } \\
\hline Simple Triangle & $0.4095^{* *}$ & $1.0224^{* *}$ & 0.7809 & 1080.520 & 15.56 \\
\hline Simple Sine & $0.6651^{* *}$ & $0.9341^{* *}$ & 0.7862 & 1075.628 & 15.04 \\
\hline Double Triangle & $0.5561^{* *}$ & $0.9753^{* *}$ & 0.7783 & 1080.996 & 15.61 \\
\hline Double Sine & $0.8028^{* *}$ & $0.8897^{* *}$ & 0.7749 & 1075.971 & 15.07 \\
\hline Simple Logistic & 0.1102 & $1.0498^{* *}$ & 0.7693 & 1015.157 & 8.57 \\
\hline Simple Normal & -0.1858 & $1.1933^{* *}$ & 0.6681 & 1059.475 & 13.31 \\
\hline Double Logistic & 0.2675 & $0.9993^{* *}$ & 0.7723 & 1015.688 & 8.62 \\
\hline Double Normal & 0.0862 & $1.1373^{* *}$ & 0.7219 & 1089.645 & 16.53 \\
\hline Ref. Standard & & & & 935.019 & \\
\hline \multicolumn{6}{|c|}{ Carepa } \\
\hline Simple Triangle & $0.2855^{* *}$ & $0.9884^{* *}$ & 0.7565 & 373.550 & 14.71 \\
\hline Simple Sine & 0.45602 & $0.89081^{* *}$ & 0.7655 & 372.629 & 14.43 \\
\hline Double Triangle & $0.3539^{* *}$ & $0.9506^{* *}$ & 0.7560 & 373.611 & 14.73 \\
\hline Double Sine & $0.5605^{* *}$ & $0.9181^{* *}$ & 0.6262 & 400.447 & 22.97 \\
\hline Simple Logistic & 0.0287 & $1.0554^{* *}$ & 0.7413 & 348.866 & 7.13 \\
\hline Simple Normal & -0.2287 & $1.2594^{* *}$ & 0.7324 & 368.739 & 13.23 \\
\hline Double Logistic & 0.10379 & $1.0139^{* *}$ & 0.7483 & 348.9689 & 7.16 \\
\hline Double Normal & -0.0619 & $1.1929^{* *}$ & 0.7408 & 377.2591 & 15.85 \\
\hline Ref. Standard & & & & 325.647 & \\
\hline \multicolumn{6}{|c|}{ Ciudad Bolívar } \\
\hline Simple Triangle & $1.6987^{* *}$ & $0.8798^{* *}$ & 0.8909 & 747.189 & 24.10 \\
\hline Simple Sine & $1.8946^{* *}$ & $0.8908^{* *}$ & 0.6908 & 786.122 & 30.57 \\
\hline Double Triangle & $1.7353^{* *}$ & $0.8692^{* *}$ & 0.8690 & 745.4369 & 23.81 \\
\hline Double Sine & $1.9452^{* *}$ & $0.8899 * *$ & 0.6923 & 784.8356 & 30.35 \\
\hline Simple Logistic & $1.2584^{* *}$ & $0.8967^{* *}$ & 0.8889 & 700.9998 & 16.43 \\
\hline Simple Normal & $1.0823^{* *}$ & $0.9873^{* *}$ & 0.8540 & 732.9957 & 21.74 \\
\hline Double Logistic & $1.2948^{* *}$ & $0.8859^{* *}$ & 0.8714 & 699.1368 & 16.12 \\
\hline Double Normal & $1.0870^{* *}$ & $0.9988^{* *}$ & 0.8517 & 740.5252 & 22.99 \\
\hline Ref. Standard & & & & 602.089 & \\
\hline
\end{tabular}

${ }^{¥}$ Accumulated Degree-days. Statistical significance $(\mathrm{p}<0.05)$ indicated by “*”, $(\mathrm{p}<0.01)$ indicated by “**”. New methods indicated in bold type. Ref. standard = Reference standard 


\section{Santa Elena, Antioquia}

All the models presented higher $\mathrm{R}^{2}$ values, and therefore better fit, in this region than in Cajicá, (Table 1). The intercepts were statistically significant for all previously proposed methods, while the intercepts for all the new methods were not significant. The four previously proposed methods showed the highest $\mathrm{R}^{2}$ values, but also high values of bias close to $15 \%$. The Simple Normal and Double Normal methods also had high bias. Alternatively, the Simple Logistic and Double Logistic methods showed a much lower bias close to $8.0 \%$ and $\mathrm{R}^{2}$ values of 0.76 and 0.74 , respectively, values that are very close to those obtained by the previously proposed methods. According to these results, the Simple Logistic and Double Logistic methods presented the best performance in the Santa Elena region. The Double Normal method presented the highest bias with one of the lowest $\mathrm{R}^{2}$ values, consequently its use is not recommended in this region.

\section{Carepa, Antioquia}

From all the evaluated methods, only the Simple Triangle, Double Triangle, and Double Sine methods had models with statistically significant intercepts. The previously published methods showed biases ranging from $14 \%$ to almost $23 \%$, while the proposed methods, with the exception of the Double Normal, presented lower biases. The Simple Logistic and Double Logistic methods had biases of $7.13 \%$ and $7.16 \%$, respectively, which are practically half of those obtained with the previously proposed methods. The Simple Logistic and Double Logistic methods also had $\mathrm{R}^{2}$ values close to 0.74 , which can be considered appropriate compared to those obtained by the other methods. Even though the Double Normal method showed a better $\mathrm{R}^{2}$ value than in the other regions, it is not recommended because it has a bias of $15 \%$, which doesn't represent an improvement over the previously proposed methods.

\section{Ciudad Bolívar, Antioquia}

The $\mathrm{R}^{2}$ values tended to be higher in this locality. A noticeable exception occurred with the Simple Sine and Double Sine methods, whose models had coefficients of determination that indicate a particularly poor fit. Bias values were also higher in this locality for all the methods. For the previously proposed methods, the bias ranged from $24 \%$ to $30 \%$ while the new methods had biases between $16 \%$ and $23 \%$, with the highest value being that of the Double Normal method. As in the previous localities, the Simple Logistic and Double Logistic methods had the lowest biases with values close to $16 \%$ and acceptable $\mathrm{R}^{2}$ values that allow recommending these methods for this locality.

The differences among methods were evident and consistent throughout the localities, making it easier to select the best methods. The previously published methods presented acceptable coefficients of determination, but they are not recommended because they showed a tendency to have higher biases than the new methods in all the environments. In many cases the models of the new methods didn't have statistically significant intercepts, which is a desirable property that indicates that those methods would estimate a degree-day value close to zero when the reference standard method actually calculates a degree-day value of zero. The Double Normal method had a poor performance and therefore is not recommended. The Simple Logistic and Double Logistic methods had acceptable coefficients of determination along with noticeably lower biases than the other methods. Given that this result was consistent in the four different agroecological localities, these two methods can be recommended to be used in Colombia.

There were differences in the performance of the methods among localities, which is consistent with the results found by Routsch et al. (1999), who found that using the Simple Triangle method, the percentage error in degree-day estimation in the Intermediate Valley of California was much higher than in the Interior Valley. In this research the best goodness of fit was observed in Ciudad Bolivar, where the average coefficient of determination was 0.825 . Santa Elena and Carepa had intermediate $\mathrm{R}^{2}$ values, 0.753 and 0.733 respectively. The poorest fit was found in Cajicá, where the average coefficient of determination was 0.576 . Localities like Cajicá, located in a Lower Montane dry forest life zone and at $2558 \mathrm{~m}$., have big variations in cloudiness and wind speed during a single day. These variations could possibly have great effect on the daily temperature fluctuation, which affects the goodness of fit of any degree-day accumulation model based on the minimum and maximum temperatures. In such cases, a solution would be to calculate degree-days through hourly temperature data, or to use models based on the characterization of the specific daily temperature for the region of interest. The latter alternative was evaluated by SAMSON (1984), who estimated accumulated degreedays for Pieris rapae L. (Lepidoptera: Pieridae) under Canberra conditions using two methods called Skewed Sine and Cycle Points, and found that the latter method gave better predictions while the former consistently overestimated the degree-days. Those overestimations fluctuated according to the month of the year between $3.6 \%$ and $60 \%$ for the Skewed Sine method while the Cycle Points method had underestimations of $7.4 \%$ at most, and its maximum overestimations reached $30 \%$. The overestimations in the present research, measured 
through the bias, were noticeably lower and none of the methods had a bias higher than $31 \%$. Even though higher variations could be found if the evaluations were done monthly, they wouldn't be as big as the variations observed in regions with seasons.

In this discussion, the bias was considered as the parameter of higher importance to evaluate the goodness of fit of the models because biased accumulations of thermal time lead to inaccurate predictions of the phenological events. If the estimated degree-day accumulation is higher than the real one, the chronological time required for the phenological event will be lower than the real and vice versa, and this could lead to very variable results in terms of population dynamics (Bryant et al. 1998). Finally, it is important to take into account that even though factors like diet in the case of insects or soil fertility and humidity in the case of plants can affect development time, their effect is difficult to measure and relatively small when compared to the effect of temperature, and therefore degree-day estimation remains an important tool in the prediction of phenological events both in plants and insects (Herms, 2007).

\section{CONCLUSION}

The evaluated methods showed differences in their performance that made possible the selection of the Simple Logistic and Double Logistic methods as the best options for degree-day estimation. Since this result was consistent in all the localities, it is assumed that both methods can be used under different environmental conditions in the Colombian tropics. The Simple Normal and Double Normal methods are not recommendable because their models showed poor fit and high bias.

\section{REFERENCES}

ALLEN, J.C. A modified sine wave method for calculating degree days. Environmental Entomology, v.5, p.388-396, 1976.

ALLEN, E.J.; O'BRIEN, P.J. The practical significance of accumulated day degrees as a measure of physiological age of seed potato tubers. Field Crops Research, v.14, p.141-151, 1986.

BASKERVILLE, G.L.; EMIN, P. Rapid Estimation of heat accumulation from maximum and minimum temperatures. Ecology, v.50, p.514-517, 1969.

BELL, M.J.; WRIGTH, G.C. Groundnut growth and development in contrasting environments. 2. Heat unit accumulation and photothermal effects on harvest index. Experimental Agriculture, v.34, p.113-124, 1998

BROUFAS, G.D.; KOVEOS, D.S. Threshold temperature for post-diapause development and degree-days to hatching of winter eggs of the European red mite. (Acari: Tetranychidae) in Northern Greece. Environmental Entomology, v.24, p.703-713, 2000.
BRYANT, S.R.; BALE, J.S.; THOMAS, C.D. Modification of the Triangle method of degree-day accumulation to allow for behavioral thermoregulation in insects. Journal of Applied Ecology, v.35, p.921-927, 1998.

ELLIOT, R.H.; MANN, L.; OLFERT, O. Calendar and degree day requirements for emergence of adult wheat midge, Sitodiplosis mosellana (Géhin) (Diptera:Cecidomyiidae) in Saskatchewan, Canada. Crop Protection, v.28, p.588-594, 2009.

FOX, J. Nonlinear regression and nonlinear least-squares. Available at: http://cran.r-project.org/doc/contrib/Fox-Companion/appendixnonlinear-regression.pdf. 2002. Accessed 27th. Nov. 2009.

GUAN, B.T.; CHUNG, C.H.; LIN, S.T.; SHEN, C.W. Quantifying height growth and monthly growing degree days relationship of plantation Taiwan spruce. Forest Ecology and Management, v.257, p.2270-2276, 2009.

HART, A.J.; BALE, J.S.; FENLON, J.S. Developmental threshold, day-degree requirements and Voltinism of the aphid predator. Epysirphus balteatus (Diptera: Syrphidae). Annals of Applied Biology, v.130, p.427-437, 1997.

HERMS, D.A. Using degree-days and plant phenology to predict pest activity. In: IPM of Midwest landscapes: tactics and tools for IPM. The Ohio State University 2007. Available from: http:// www.entomology.umn.edu/cues/Web/049DegreeDays.pdf. Accessed in: Nov., 292009.

HIRATA, M.; HIGASHI, S. Degree-day accumulation controlling allopatric and sympatric variations in the sociality of sweat bees Lasioglossum (Evylaeus) baleicum (Hymenoptera:Halictidae). Behavioral Ecology and Sociobiology, v.62, p.1239-1247, 2008.

JONES, E.A.; REED, D.D.; CATTELINO, P.J.; MROZ, G.D. Seasonal shoot growth of planted red pine predicted from air temperature degree days and soil water potential. Forest Ecology and Management, v.46, p. 201-214, 1991.

JUlliEN, A.; CHILlET, M.; MALÉZIEUX, E. Pre-harvest growth and development, measured as accumulated degree-days, determine the post-harvest green life of banana fruit. Journal of Horticultural Science and Biotechnology, v.83, p.506-512, 2008.

KUMRAL, N.A.; KOVANCI, B.; AKBUDAK, B. Using degreeday accumulation and host phenology for predicting larval emergence patterns of the olive psyllid, Euphyllura Phyllireae. Journal of Pest Science, v.81, p.63-69, 2008.

LEMOS, J.P.; VILLA, N.A.; SILVERIA, H. A model including photoperiod in degree days for estimating Hevea bud growth. International Journal of Biometeorology v.41, p.1-4, 1997.

LINDBLAD, M.; SIGVALD, R. A degree-day model for regional prediction of first occurrence of fruit flies on oats in Sweden. Crop Protection, v.15, p.559-565, 1996

LINDSEY, A.A.; NEWMAN, J.E. Use of Official Weather Data in Spring Time: Temperature Analysis of an Indiana Phenological Record. Ecology v.37, p.812-823,1956.

MCBETH, L.J.; COFFEY, K.P.; KOBLENTZ, W.K.; TURNER, J.E.; SCARBROUGH, D.A.; BAILEY, C.R.; STIVARIUS, M.R. 
Impact of heating degree-day accumulation during Bermuda Grass hay storage on nutrient utilization by lambs. Journal of Animal Science, v.79, p.2698-2703, 2001.

MCMASTER, G.S.; WILHELM, W.W. Growing degree-days: one equation, two interpretations. Agricultural and Forest Meteorology, v.87, p.291-300, 1997.

MILONAS, P.G.; SAVAPOULOU-SOULTANI, M.; STAVRIDIS, D.G. Day-degree models for predicting the generation time and flight activity of local populations of Lobesia botrana (Den \& Schiff) (Lep.,Tortricidae) in Greece. Journal of Applied Entomology, v.125, p.515-518, 2001.

NARWAL, S.S.; POONIA, S.; SINGH, G.; MALIK, D.S. Influence of sowing dates on the growing degree days and phenology of winter maize (Zea mays L.). Agricultural and Forest Meteorology, v.38, p.47-57, 1986 .

NAVES, P.; SOUSA, E. Threshold temperatures and degree-day estimates for development of post-dormancy larvae of Monochamus Galloprovincialis (Coleoptera:Cerambicidae). Journal of Pest Science, v.82, p.1-6, 2009.

NIETSCHKE, B.; MAGAREY, R.D.; BORCHERT, D.M.; CALVIN, D.D.; JONES, E. A developmental database to support insect phenology models. Crop Protection, v.26, p.1444-1448, 2007.

OLSEN, A.; BALE, J.S.; LEADBEATER, B.S.C.; CALLOW, M.E.; HOLDEN J.B. Developmental thresholds and daydegree requirements of Paratanytarsus grimmii and Corynoneura scutellata (Diptera: Chironomidae): two midges associated with potable water treatment. Physiological Entomology, v.28, p.315-322, 2003.
ROLTSCH, W.J.; ZALOM, F.G.; STRAWN, A.J.; STRAND, J.F.; PITCAIRN, M.J. Evaluation of several degree-day estimation methods in California climates. International Journal of Biometeorology, v.42, p.169-176, 1999.

SAMSON, P.R. Interpolating temperatures for simulation of the developmental progress of Pieris rapae (L.) (Lepidoptera:Pieridae). Journal of the Australian Entomological Society, v.23, p.127-131, 1984.

SEVACHERIAN, V.; STERN, V.M.; MUELLER, A.J. Heat accumulation for timing Lygus control measures in a safflowercotton complex. Journal of Economic Entomology, v.70, p.399402, 1977.

SHARRATT, B.S.; SHEAFFER, C.C.; BAKER, D.G. Base temperature for the application of the growing-degree-day model to field-grown alfalfa. Field Crops Research, v.21, p.95-102, 1989.

SPENCER, D.F.; KSANDER, G.G.; MADSEN, J.D.; OWENS, C.S. Emergence of vegetative propagules of Potamogeton nodosus, Potamogeton pectinatus, Vallisneria americana, and Hydrilla verticillata based on accumulated degree-days. Aquatic Botany, v.67, p.237-249, 2000 .

SPENCER, D.F.; KSANDER, G.G. Estimating Arundo donax ramet recruitment using degree-day based equations. Aquatic Botany, v.85, p.282-288, 2006.

TOKESHI, M. Life cycle and production of the burrowing mayfly, Ephemera danica: A new method for estimating degree-days required for growth. Journal of Animal Ecology, v.54, p.919-930, 1985.

UNDERSANDER, D.J.; CHRISTIANSEN, S. Interactions of water variables and growing degree days on heading phase of winter wheat. Agricultural and Forest Meteorology, v.38, p.169-180, 1986. 